\title{
Estimating the scale of chronic hepatitis $C$ virus infection in the EU/EEA: a focus on migrants from anti-HCV endemic countries
}

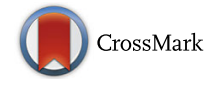

\author{
A. M. Falla ${ }^{1,2^{*}{ }^{+}}$, A. A. Ahmad ${ }^{3,4 \dagger}$, E. Duffell ${ }^{5}$, T. Noori ${ }^{5}$ and I. K. Veldhuijzen ${ }^{2,6}$
}

\begin{abstract}
Background: Increasing the proportion diagnosed with and on treatment for chronic hepatitis $\mathrm{C}(\mathrm{CHC})$ is key to the elimination of hepatitis C in Europe. This study contributes to secondary prevention planning in the European Union/ European Economic Area (EU/EEA) by estimating the number of CHC (anti-HCV positive and viraemic) cases among migrants living in the EU/EEA and born in endemic countries, defining the most affected migrant populations, and assessing whether country of birth prevalence is a reliable proxy for migrant prevalence.

Methods: Migrant country of birth and population size extracted from statistical databases and anti-HCV prevalence in countries of birth and in EU/EEA countries derived from a systematic literature search were used to estimate caseload among and most affected migrants. Reliability of country of birth prevalence as a proxy for migrant prevalence was assessed via a systematic literature search.
\end{abstract}

Results: Approximately $11 \%$ of the EU/EEA adult population is foreign-born, $79 \%$ of whom were born in endemic (anti$\mathrm{HCV}$ prevalence $\geq 1 \%$ ) countries. Anti-HCV/CHC prevalence in migrants from endemic countries residing in the EU/EEA is estimated at 2.3\%/1.6\%, corresponding to $~ 580,000 \mathrm{CHC}$ infections or 14\% of the CHC disease burden in the EU/EEA. The highest number of cases is found among migrants from Romania and Russia (50-60,000 cases each) and migrants from Italy, Morocco, Pakistan, Poland and Ukraine (25-35,000 cases each). Ten studies reporting prevalence in migrants in Europe were identified; in seven of these estimates, prevalence was comparable with the country of birth prevalence and in three estimates it was lower.

Discussion: Migrants are disproportionately affected by $\mathrm{CHC}$, account for a considerable number of $\mathrm{CHC}$ infections in EU/EEA countries, and are an important population for targeted case finding and treatment. Limited data suggest that country of birth prevalence can be used as a proxy for the prevalence in migrants.

Keywords: Chronic viral hepatitis, Hepatitis C virus (HCV), Migrants, Epidemiology, Europe

\section{Background}

Chronic infection with the hepatitis $\mathrm{C}$ virus (HCV) is a global public health challenge and a leading cause of liver disease-related morbidity and mortality. The epidemiology remains poorly understood, however, and global, national and risk group-specific anti-HCV and viraemic prevalence estimates vary considerably. Recent

\footnotetext{
* Correspondence: am.falla@rotterdam.nl; abby.falla@gmail.com ${ }^{\dagger}$ Equal contributors

'Department of Public Health, Erasmus MC, University Medical Center Rotterdam, Rotterdam, the Netherlands

${ }^{2}$ Division of Infectious Disease Control, Municipal Public Health Service Rotterdam-Rijnmond, PO Box 70032, 3000, LP, Rotterdam, The Netherlands Full list of author information is available at the end of the article
}

studies suggest that between 105 million and 185 million people are anti-HCV positive worldwide and that global anti-HCV prevalence in adults could be as high as $2 \%$ $[1,2]$. The Global Burden of Disease study estimated that chronic $\mathrm{HCV}(\mathrm{CHC})$ infection causes almost half a million deaths annually and is the 25th leading cause of death worldwide [3].

Chronic HCV infection affects the liver and has a mostly asymptomatic onset, but can lead to cirrhosis and hepatocellular carcinoma (HCC) decades later [4]. The asymptomatic nature of infection and the lack of adequate screening programmes means that the majority of people infected with $\mathrm{CHC}$ are unaware of their 
infection and only around one third of all estimated $\mathrm{CHC}$ infections in Europe have been diagnosed [5-7]. Effective antiviral treatment can prevent the development of cirrhosis and HCC and, with newer direct acting antivirals (DAAs) reporting cure rates in more than $90 \%$ of cases, [8] the elimination of $\mathrm{HCV}$ infection is now possible in Europe [9]. This will require continued primary prevention of new infections in parallel with expansion of secondary prevention through effective screening, linkage to care and treatment.

Primary prevention measures in Europe, including a safe blood supply, improved infection control practices and harm reduction programmes, have led to a significant reduction of $\mathrm{HCV}$ transmission in many countries and a mathematical modelling study shows incident cases are declining [10]. Incident data is not systematically collected and reported in most EU/EEEA countries hampering a good understanding of time trends although iatrogenic and nosocomial transmission is reported to be rare in most EU/EEA countries [11]. However, models predict that the peak in the mortality is yet to be reached $[9,10,12]$. An estimated 7.4 million people are anti-HCV positive in the European Union/ European Economic area (EU/EEA), although prevalence varies from $0.9 \%$ in Western Europe to $3.3 \%$ in Eastern Europe $[1,13]$. Deaths from viral hepatitis now exceed those from HIV and tuberculosis combined and latest published estimates show that 96,000 people die each year in EU/EEA countries from HBV and HCV-related liver disease [3]. Some populations are disproportionately affected and have a high prevalence of chronic infection. One such population is migrants born in high anti-HCV prevalence countries [10, 14-16], although estimates of the number of cases and the most affected migrant populations in Europe are lacking.

This epidemiological study seeks to inform targeted screening, linkage to care and treatment in the EU/EEA by: providing estimates, across and within all $31 \mathrm{EU} /$ EEA countries, of the number of $\mathrm{CHC}$ cases among migrants from countries where anti-HCV prevalence is $\geq 1 \%$; providing an estimate of the relative contribution of migrants to the overall burden of disease; and comparing the reported in-country of birth prevalence with that found among migrants living in European countries. In a sister paper to this, we conduct a similar analysis for chronic hepatitis B among migrants from endemic countries.

\section{Methods}

The data retrieval and analysis process are described in detail below and in a schematic representation (Fig. 1). Demographic data on the size of and countries of birth of migrant populations were extracted from statistical databases. Country of birth-specific and EU/EEA country general population anti-HCV prevalence estimates were derived from a systematic literature search. To assess the reliability of using country of birth-derived prevalence as a proxy for the prevalence among migrants, a systematic literature search was conducted to identify prevalence estimates among migrants in Europe to compare with country of birth-derived prevalence.

\section{Definitions \\ Migrant}

An adult 15 years old or above, born in a country other than the current country of residence. Children are excluded due to the dominance of older age populations in sero-prevalence studies and the higher prevalence reported among adults than among children [1]. The use of the term 'migrant' in this study therefore refers to adult (foreign-born) migrants only. The study accounts for and includes migration from outside the EU/EEA and migration within the EU/EEA, but excludes undocumented migrants.

\section{Anti-HCV prevalence}

The common measure of exposure to $\mathrm{HCV} /$ endemicity used in sero-prevalence studies. Anti-HCV prevalence can include exposed individuals with a resolved infection.

\section{Chronic hepatitis $\mathrm{C}$ (CHC)}

Refers to viraemic infection, i.e. anti-HCV and HCVRNA positivity. Endemic country: the anti-HCV prevalence in the general adult population is $\geq 1 \%$. This relatively low threshold was chosen to take into account migrants from countries where prevalence is higher than that of the EU/EEA as a whole.

\section{Part 1: The contribution of migrants from endemic countries to the burden of CHC in the EU/EEA Demographic data (Step 1)}

The size and country of birth of the migrant population was obtained for all 31 EU/EEA countries from Eurostat for 2013, if available [17]. Where data were unavailable, either the 'EU 2011 - Housing and Population Census', the most recent demographic data from the Organisation for Economic Co-operation and Development (OECD) Stats website or national statistics were used, in that order [18-20]. The data source is indicated in footnotes in Table 1. For each EU/EEA country, the countries of birth of migrants were sorted into descending order of magnitude of the number of migrants, and the top 50 countries of birth by migrant population size were then selected for estimating the $\mathrm{CHC}$ burden.

\section{Country-specific anti-HCV prevalence (Step 2)}

The online databases Medline, Embase, the Cochrane library, Web of Science, Scopus, PubMed publisher and 


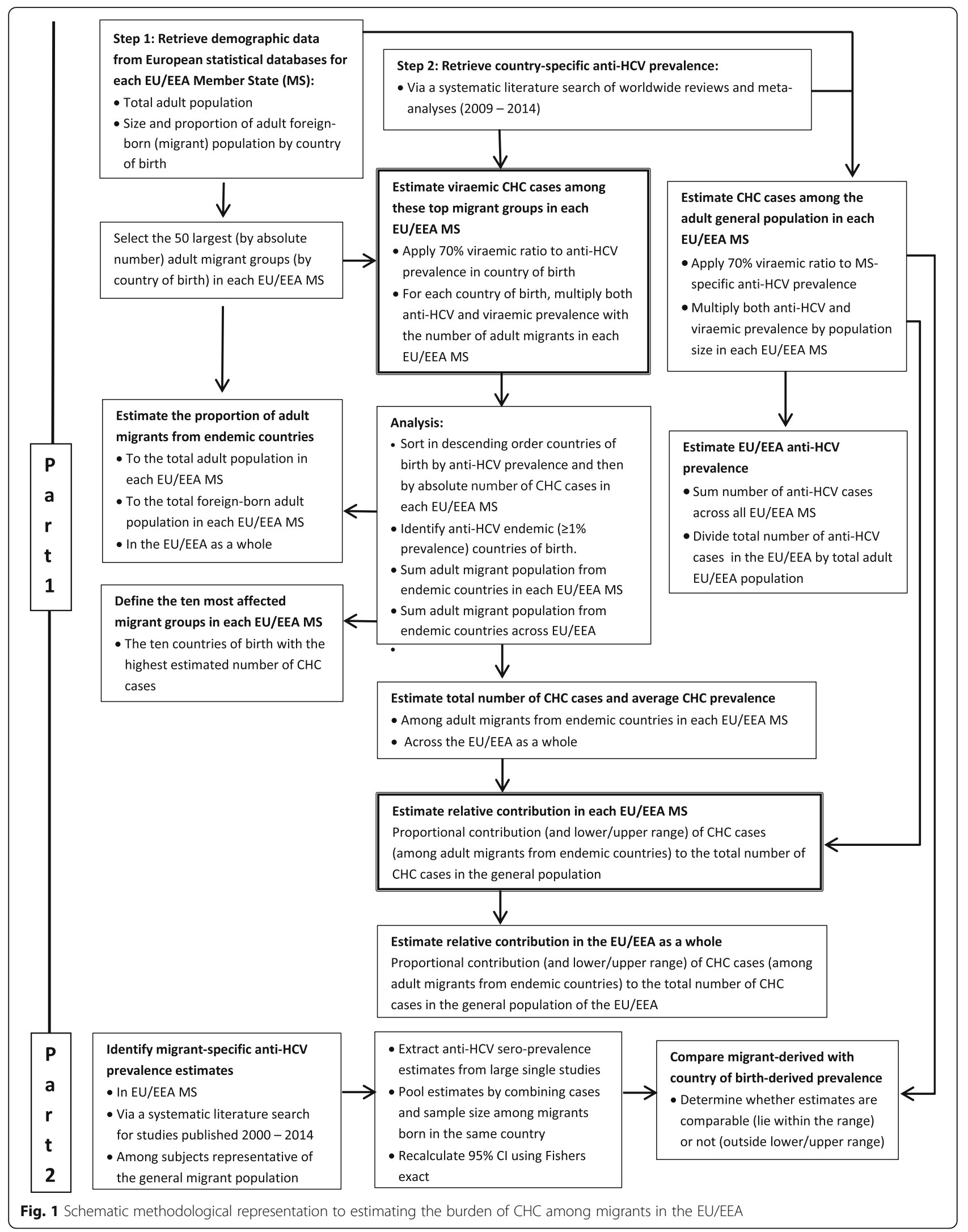




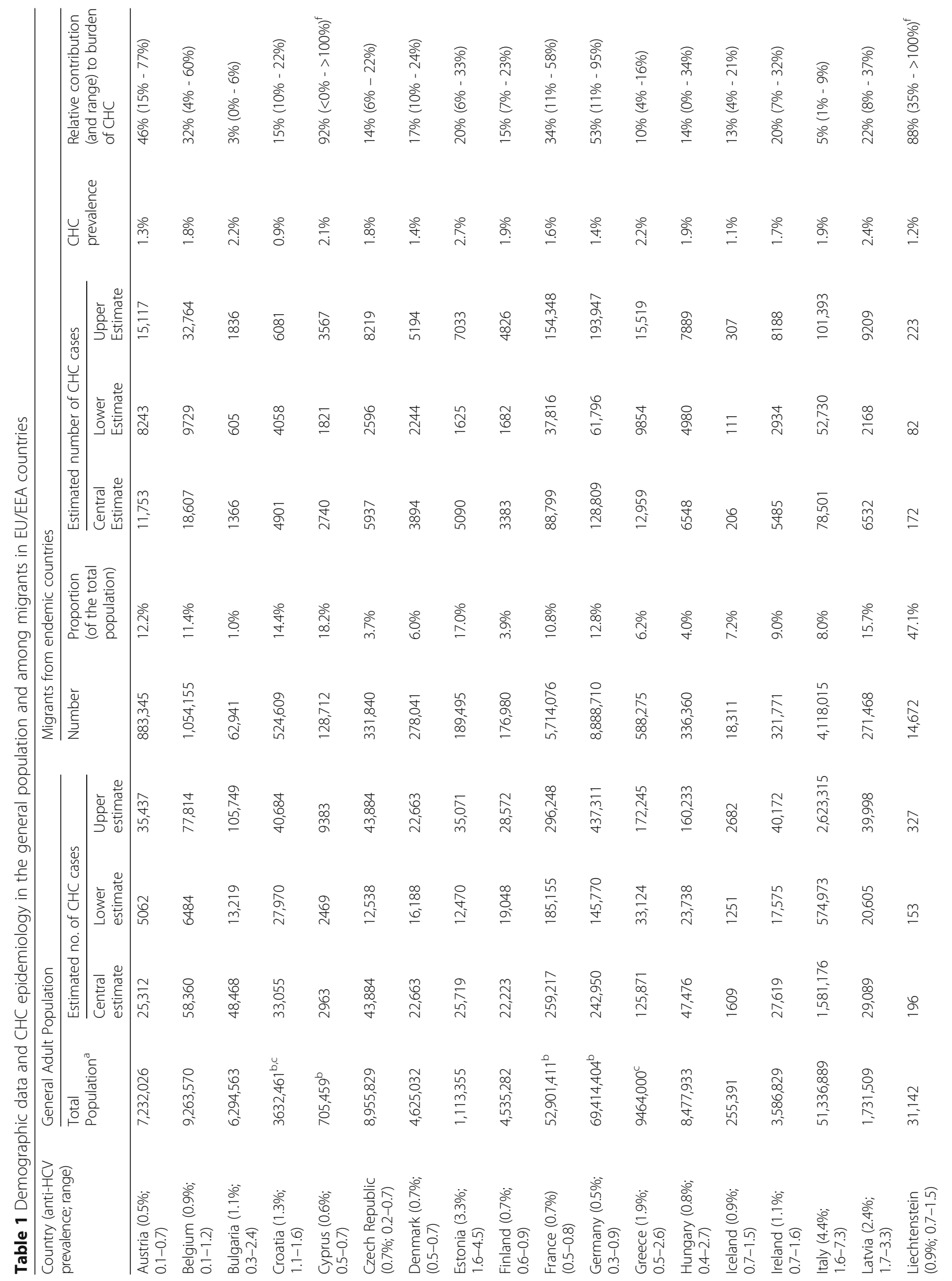




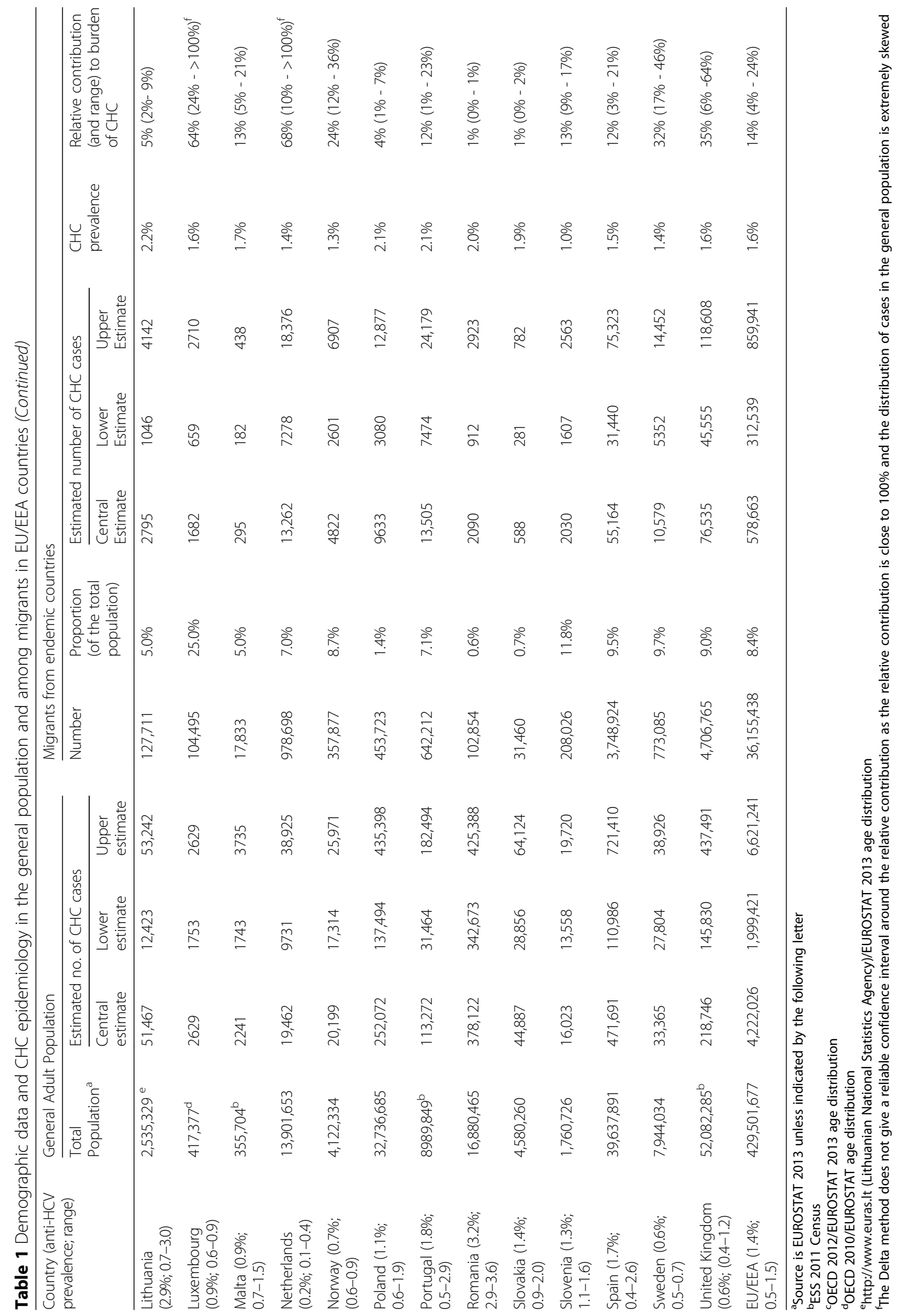


Google Scholar were searched in January 2015 for reviews, systematic reviews and meta-analyses in English about the prevalence of hepatitis $\mathrm{C}$ in the general population at country level. The search (described in full in Annex 1 of the Additional file 1) used a combination of disease-related (hepatitis C), outcome-related (prevalence), population-related (general population, worldwide) and study design-related (reviews) terms. Note that the search also included terms related to hepatitis B since we conducted a similar analysis for chronic hepatitis B among migrants from endemic countries (to be published in this journal). Since the aim was to identify recent reviews, the search was restricted to papers published after 2009 to the date of the search. The titles and abstracts, then the full text, of retrieved citations were assessed for relevancy by one reviewer (AF). Key exclusion criteria included studies focused on: hepatitis other than type $C$; natural history, clinical features or complications of hepatitis; medical treatment; other high risk groups e.g. people who inject drugs (PWID); and single case studies and cost effectiveness analyses. High quality systematic reviews/meta-analyses were selected given the recent publication of robust systematic reviews/metaanalyses of national level prevalence estimates globally.

Country-level anti-HCV prevalence estimates and uncertainty ranges/confidence intervals (CIs) were extracted from the included reviews and entered into a Microsoft Excel database of all countries. Where a country-specific estimate was unavailable, the relevant Global Burden of Disease region estimate was used. If a meta-analysis reported a statistically significant time trend, the estimate from the most recent period was selected. Where multiple estimates for a country were available from different reviews, the most robust was selected based on the assessed risk of selection bias. Risk of selection bias was assessed based on: sampling method (random favoured over convenience); sampling population (the general population was favoured over more specifically defined (risk) groups); geographical coverage (national favoured over regional; regional favoured over local); sample size (larger studies preferred over smaller one); and data collection timeframe (favouring recency). Decisions were made jointly by two reviewers (AF and IV) based on these criteria (rather than a pre-defined algorithm) with a detailed rationale recorded for each selected estimate. This rationale, together with search strategy, the inclusion/exclusion criteria and a PRISMA flowchart are available in the online supplement.

\section{Estimating the $\mathrm{CHC}$ burden among migrants from endemic countries}

Anti-HCV prevalence was multiplied by the number of migrants from the top 50 countries of birth of migrants in each EU/EEA country. The countries of birth were then sorted in descending order of magnitude by anti$\mathrm{HCV}$ prevalence to identify all endemic ( $\geq 1 \%$ anti-HCV prevalence) countries. The total number of migrants born in anti-HCV endemic countries was used to determine both the total and proportional contribution of migrants from these countries to the overall number of migrants residing in each of the 31 EU/EEA countries. To estimate the proportion of $\mathrm{CHC}$ (viraemic) cases among the anti-HCV positive migrant population, the worldwide average viraemic proportion of $70 \%$ found in a recent global meta-analysis was applied [1].

\section{Relative contribution}

For each EU/EEA country, the estimated number of infected cases among migrants from endemic countries was divided by the total number of infected persons (based on the general population $\mathrm{CHC}$ prevalence estimate and the total population) to estimate the relative contribution of migrants from endemic countries to the overall number of people infected with $\mathrm{CHC}$. Given uncertainty in both the size of the migrant population and $\mathrm{CHC}$ prevalence estimates in countries of birth, a range in the relative contribution (a lower limit and a higher limit) was also calculated using the Delta method [21].

\section{Part 2: Anti-HCV prevalence in migrant populations in Europe}

The online databases Medline, Embase, the Cochrane library, Web of Science, Scopus, PubMed publisher and Google Scholar were searched in November 2014 for studies in English that estimate the prevalence of hepatitis $\mathrm{C}$ in migrants in any of the 31 EU/EEA countries. The search used a combination of disease-related (hepatitis C), outcome-related (prevalence), population-related (migrants) and geographical area (EU/EEA countries) terms and was limited to studies published between 2000 and 2014. We expected a limited retrieval from this search and therefore included only selection bias (how representative the study population was of the general population) as a key parameter in the risk of bias assessment. This operationalised through the exclusion of studies sampled from higher risk migrant groups such as refugees/asylum seeker and higher risk (general) populations such as STI clinic attendees, outpatient clinics, international health centres etc. The full search strategy, inclusion/exclusion criteria and PRISMA flowchart are available in the online supplement.

Data from the included studies were entered into Microsoft Excel. Pooled estimates for countries of birth were produced by combining the numbers tested and the number of cases. A 95\% CI was re-calculated using the Fisher's exact method. Prevalence estimates pooled from multiple studies or extracted from large single 
studies ( $>25$ subjects from a single country) were compared with the in-country estimates to determine whether in-country estimates reflect the prevalence found among migrants. When the point prevalence from a study in migrants (Part 2) fell within the CI/uncertainty range of the in-country estimate (from Part 1), this estimate was considered to be comparable; when it fell below the lower $\mathrm{CI} /$ uncertainty range, it was considered to be lower than the in-country prevalence; and when it was higher than the upper $\mathrm{CI} /$ uncertainty range, it was considered to be higher.

\section{Results}

Estimated $\mathrm{CHC}$ prevalence and number of infected cases in $31 \mathrm{EU} / \mathrm{EEA}$ countries (Table 1)

The anti-HCV prevalence in the general population in the EU/EEA is estimated at $1.4 \%$ (range of $0.7-2.2 \%$ ). However, prevalence estimates range from $0.2 \%$ in the Netherlands to $4.4 \%$ in Italy and 14 EU/EEA countries are considered endemic by the definition adopted in our study ( $\geq 1 \%$ anti-HCV prevalence). Table 1 lists the estimated number and range of $\mathrm{CHC}$ cases among adults in EU/EEA countries. An estimated 4.2 million (range 2.06.6 million) adults in the EU/EEA have CHC infection. Italy has the highest absolute number, with an estimated 1.6 million $\mathrm{CHC}$ cases. Other EU/EEA countries with a high absolute number of $\mathrm{CHC}$ cases among adults are Romania, with 380,000, and Spain, with 470,000.

The distribution of migrants in the EU/EEA based on HCV endemicity in country of birth

The top 50 migrant populations in each EU/EEA country included in the analysis make up at least $95 \%$ of the total migrant population in 19 countries and at least 90\% in all but three EU/EEA countries (Denmark,
Sweden and the United Kingdom, where the proportion is at least $85 \%$ ). These migrant populations account for approximately $10.7 \%$ of the total adult population in the EU/EEA although the proportion in each country varies, ranging from $0.7 \%$ in Romania, $1.1 \%$ in Bulgaria and $1.7 \%$ in Poland to $42.0 \%$ in Luxembourg and $65.2 \%$ in Liechtenstein (Fig. 2).

Nearly $80 \%$ of the total migrant population were born in $\mathrm{HCV}$ endemic countries. Other than in Slovakia, where $23 \%$ of the total migrant population are from endemic countries, over half of all migrants in the other 30 EU/EEA countries were born in countries where the anti-HCV prevalence is $\geq 1 \%$. In Croatia, Estonia, Latvia, Lithuania, Romania and Slovenia, more than $90 \%$ of all migrants are from endemic countries (Fig. 2). The number and proportion of all migrants that from endemic countries, at country level and in the EU/EEA as a whole are shown in Table 2.

\section{Country-specific anti-HCV prevalence estimates}

The most comprehensive review with country-specific estimates of anti-HCV prevalence identified by the search was published in 2014 by Gower et al. [1]. This review includes studies published after the year 2000 and provides estimates for 87 countries and for each of the 21 Global Burden of Disease regions. The countrylevel estimates from Gower do not have 95\% CIs but a lower and upper uncertainty range; the lower range is based on studies among populations considered representative of 'healthy adults' (such as blood donors), but the methodology applied to derive the upper limit is unclear. For nine countries, Gower's regional or in-country estimate was replaced with estimates from other systematic reviews deemed more robust according to the criteria described in the methods [2, 22-26]. The 224

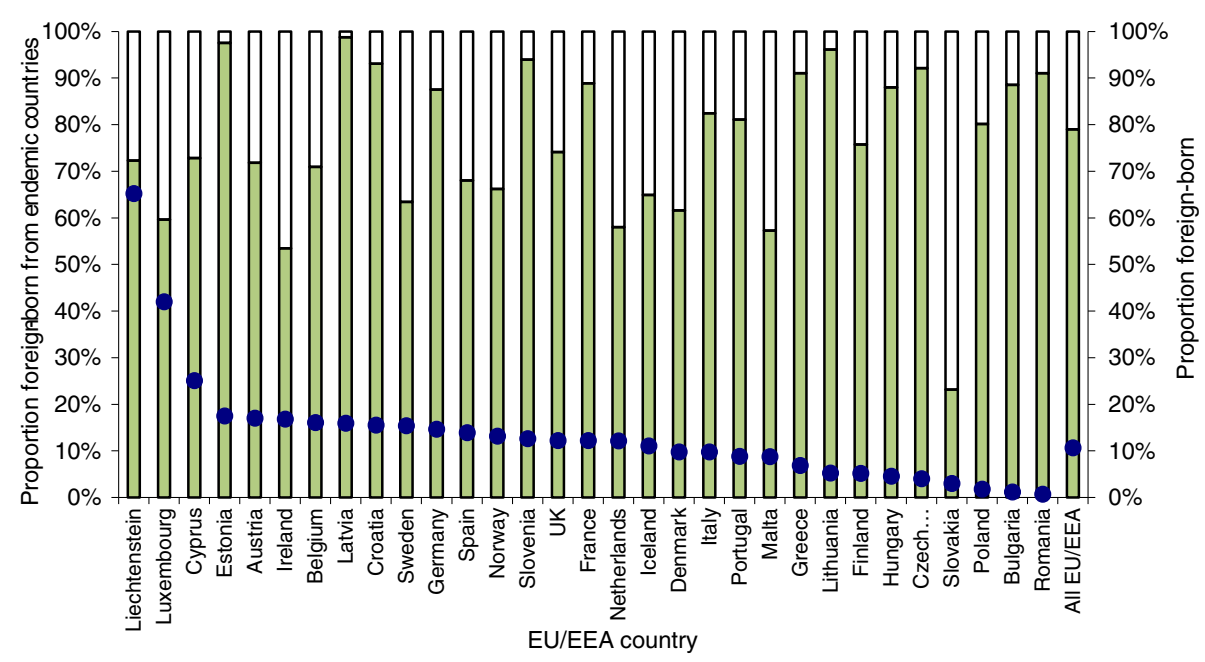

Fig. 2 Total (\%) migrant population in each EU/EEA country and the proportion born in endemic countries 
Table 2 The ten migrant groups (from endemic countries) accounting for the highest number of $\mathrm{CHC}$ cases

\begin{tabular}{|c|c|c|c|c|}
\hline Migrant country of birth & $\begin{array}{l}\text { Total adult migrant } \\
\text { population }\end{array}$ & $\begin{array}{l}\text { Anti-HCV } \\
\text { prevalence }\end{array}$ & $\begin{array}{l}\text { Number (rounded) of } \\
\text { CHC cases }\end{array}$ & Host countries (first 6 with largest populations) ${ }^{a}$ \\
\hline Romania & $2,646,392$ & 3.2 & 59,000 & Italy, Spain, Germany, Hungary, UK, Austria \\
\hline Russia & $1,713,636$ & 4.1 & 49,000 & Germany, Latvia, Estonia, Italy, Lithuania, Spain \\
\hline Italy & $1,114,683$ & 4.4 & 34,000 & $\begin{array}{l}\text { France, Germany, UK, Belgium, Spain, The } \\
\text { Netherlands }\end{array}$ \\
\hline Poland & $4,103,409$ & 1.1 & 32,000 & $\begin{array}{l}\text { Germany, UK, Italy, France, Ireland, The } \\
\text { Netherlands }\end{array}$ \\
\hline Morocco & $2,418,072$ & 1.6 & 27,000 & $\begin{array}{l}\text { France, Spain, Italy, Belgium, The Netherlands, } \\
\text { Germany }\end{array}$ \\
\hline Pakistan & 756,170 & 5.0 & 27,000 & UK, Italy, Spain, Germany, Greece, France \\
\hline Ukraine & 993,459 & 3.6 & 25,000 & $\begin{array}{l}\text { Poland, Germany, Italy, Czech Republic, Spain, } \\
\text { Latvia }\end{array}$ \\
\hline Egypt & 194,852 & 15.7 & 21,000 & Italy, UK, France, The Netherlands, Austria, Greece \\
\hline Kazakhstan & 807,781 & 3.3 & 19,000 & $\begin{array}{l}\text { Germany, Latvia, Czech Republic, Poland, } \\
\text { Lithuania, Estonia }\end{array}$ \\
\hline Nigeria & 313,212 & 8.4 & 18,000 & UK, Italy, Spain, Ireland, Austria, The Netherlands \\
\hline
\end{tabular}

${ }^{a}$ if migrant population is at least 1000

country-level prevalence estimates and the source, together with an overview of decision rationale where an estimate other than Gower was available, are listed in the online supplement.

\section{Estimated prevalence and number of $\mathrm{CHC}$ infections among migrants}

Across the EU/EEA, the overall anti-HCV prevalence among migrants from endemic countries is estimated at $2.3 \%$, which corresponds to a $\mathrm{CHC}$ prevalence of $1.6 \%$ and an estimated 580,000 CHC infections (Table 2). The estimated prevalence of $\mathrm{CHC}$ infection among migrants from endemic countries ranges from $0.9 \%$ in Croatia to 2.4\% in Estonia. Table 2 lists the ten migrant populations with the highest estimated number of $\mathrm{CHC}$ cases and the host EU/EEA countries with the largest populations of migrants born in these countries. Based on cumulative analysis of the $\mathrm{CHC}$ burden among the different migrant populations from endemic countries to or within the EU, migrants from Romania, Russia, Italy and Poland contribute most, in descending order, to the overall number of $\mathrm{CHC}$ cases. An estimated 50,000-60,000 $\mathrm{CHC}$ cases are found among migrants from Romania and from Russia.

Some countries of birth of migrants are common across EU/EEA countries. Adult migrants from Russia, a high $\mathrm{CHC}$ prevalence country $(2.9 \%)$, are represented among the top ten migrant populations in 25 of $31 \mathrm{EU} /$ EEA countries. Migrants from Romania and Italy are among the top ten migrant groups in 20 EU/EEA countries. Although small in number, migrants from Egypt are among the top ten $\mathrm{CHC}$-infected migrant populations in 16 of $31 \mathrm{EU} / \mathrm{EEA}$ countries due the very high anti-HCV prevalence (15.7\%) in Egypt. In Estonia,
Lithuania and Latvia, the top ten migrant populations with the highest number of infected cases are all from countries of the former Soviet Union. This is also the case in five to six of the top ten migrant populations with the highest number of infected cases in Bulgaria, the Czech Republic and Poland. People born either in Yugoslavia before 1992 or in one of the countries that emerged from the fall of Yugoslavia since 1992are represented in six of the top ten migrant populations with the largest of number of $\mathrm{CHC}$ cases in Croatia and Slovenia and three of the top ten in Austria. Migrants from the Algeria, Morocco and Tunisia are represented among the ten most $\mathrm{CHC}$-affected migrant populations in France. EU/EEA countries with three to five African countries represented among the top ten $\mathrm{CHC}$-affected migrant groups include Belgium, France, Luxembourg, Portugal and the UK. Prevalence, population size and number and range of $\mathrm{CHC}$ infections among, for all 50 countries of birth of migrants in each EU/EEA country can be found in the online supplement.

\section{Relative contribution of migrants to the $\mathrm{CHC}$ burden in EU/EEA countries}

The relative proportion (and range) of infected migrants from endemic countries within the overall $\mathrm{CHC}$ burden in EU/EEA countries is shown in Table 1 and Fig. 3. The relative contribution is low $(<4 \%)$ in Bulgaria, Poland, Romania and Slovakia and much higher $(64 \%-92 \%)$ in Cyprus, Liechtenstein, Luxembourg and the Netherlands.

\section{Comparing migrant-derived anti-HCV prevalence with country of birth estimates}

The literature search identified thirteen anti-HCV prevalence estimates from studies in migrants in the EU/EEA 


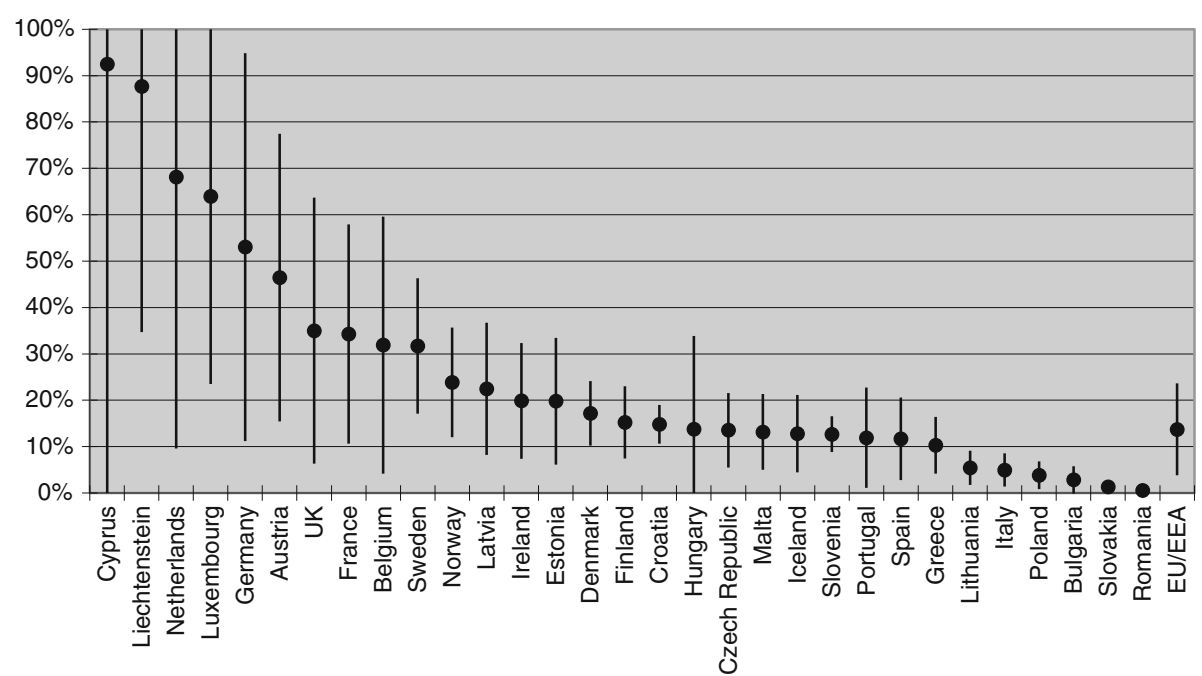

Fig. 3 Estimated relative contribution (upper/lower range) of migrants to the total number of CHC cases

for comparison with the in-country estimates derived in Part 1. Two of the thirteen estimates, from studies among migrants from the former Dutch Antilles and Suriname, were higher than the comparator regional prevalence [1]. One estimate, from a study among migrants from the former Soviet Union, could not be compared with in-country anti-HCV prevalence since this nation state is now dissolved. Of the remaining ten estimates, seven were comparable with the in-country estimate and three, among migrants from Egypt, Pakistan and Turkey, were lower than the in-country prevalence (Egypt: $2.4 \%$ in migrants vs. $15.7 \%$ incountry; Pakistan: $2.8 \%$ in migrants vs. $5.5 \%$ in-country; and Turkey: $0.2 \%$ in migrants vs. $1.0 \%$ in-country), although for Turkey the two confidence intervals overlap. See Table 3 for details.

\section{Discussion}

This is the first study we know of that attempts to systematically estimate the overall number of $\mathrm{CHC}$ cases among migrants, as well as the relative contribution of cases among migrants to the overall burden of $\mathrm{CHC}$ in EU/EEA countries. Migrants from endemic countries account for one in 12 EU/EEA adult citizens and for one in seven of all $\mathrm{CHC}$ cases in the EU/EEA. As the contribution of migrants to the overall burden of $\mathrm{CHC}$ varies between EU/EEA countries, effective approaches to secondary prevention will, therefore, also differ. Screening

Table 3 Comparing migrant study-derived prevalence to country of birth-derived prevalence

\begin{tabular}{|c|c|c|c|c|c|c|}
\hline \multirow[t]{2}{*}{ Country of birth } & \multicolumn{3}{|l|}{ Migrants } & \multicolumn{2}{|l|}{ In-country } & \multirow[t]{2}{*}{ Comparison } \\
\hline & N. tested & Prevalence $(95 \% \mathrm{Cl})$ & Reference & Prevalence $(95 \% \mathrm{Cl})$ & Reference & \\
\hline Afghanistan & 293 & $1.0(0.2-3.0)$ & [32] & $1.1(0.6-1.9)$ & [1] & Comparable \\
\hline Bangladesh & 934 & $0.4(0.1-1.1)$ & {$[52,53]$} & $1.3(0.2-2.2)$ & [1] & Comparable \\
\hline Dutch Antilles & 38 & $2.6(0.1-13.8)$ & {$[15,45]$} & $0.8^{b}(0.2-1.3)$ & [1] & Higher \\
\hline Egypt & 465 & $2.4(1.2-4.2)$ & [54] & $15.7(13.9-17.5)$ & [25] & Lower \\
\hline Former USSR & 65 & $3.1(0.4-10.7)$ & [32] & $3.3^{\mathrm{a}}(1.6-4.5)$ & [1] & Comparable \\
\hline India & 1334 & $0.4(0.2-1.0)$ & {$[52,53]$} & $0.8(0.4-1.0)$ & [1] & Comparable \\
\hline Iran & 153 & $0.7(0-3.6)$ & [32] & $0.5\left(0.2-1^{\mathrm{a}}\right)$ & [1] & Comparable \\
\hline Iraq & 290 & $0.3(0-1.9)$ & [32] & $3.2\left(0.3-3.2^{\mathrm{a}}\right)$ & [1] & Comparable \\
\hline Morocco & 331 & $0.9(0.2-2.6)$ & {$[15,45]$} & $1.6\left(0.6-1.9^{\mathrm{a}}\right)$ & [1] & Comparable \\
\hline Pakistan & 3562 & $2.8(2.3-3.4)$ & {$[30,52,53]$} & $5.5(4.4-5.5)$ & [26] & Lower \\
\hline Suriname & 225 & $2.4(0.5-7.0)$ & {$[15,45]$} & $0.8^{b}(0.2-1.3)$ & [1] & Higher \\
\hline Turkey & 965 & $0.2(0-0.8)$ & {$[15,45,46]$} & $1.0(0.7-1.1)$ & [22] & Lower \\
\hline Vietnam & 126 & $1.6(0.2-5.6)$ & [32] & $1.0(0.8-1.8)$ & [1] & Comparable \\
\hline
\end{tabular}

${ }^{\mathrm{a}}$ Regional estimate from GBD Eastern European region

${ }^{\mathrm{b}}$ Caribbean GBD Regional estimate 
programmes targeting migrant populations will be most effective in EU/EEA countries such as Austria, France, Germany, the Netherlands and the UK where migrants account for a large proportion of the disease burden (32-92\%, see Fig. 3) and a small proportion of the total population (7-15\%, see Fig. 2).

In contrast, in countries where $\mathrm{HCV}$ prevalence is high in the general population and the contribution of migrants is low, it may be more cost-effective to implement population-based screening [27, 28]. Examples of such countries include Bulgaria, Poland, Romania and Slovakia where less than $4 \%$ of the $\mathrm{CHC}$ burden is attributable to migrants from endemic countries. The differences in general population prevalence between EU/EEA countries, together with the contribution of migrants moving within the EU/EEA from high to low prevalence countries, suggests that there may also be value in allocating EU health funding to scale up and systematise screening and treatment efforts in EU/EEA countries with a high general population prevalence, to strengthen efforts to reduce cross-border health threats and to improve overall population health in the EU. A recent modelling study estimated that only around a third of all $\mathrm{CHC}$ cases across Europe have been diagnosed and that there are wide differences in both the proportion diagnosed and the proportion on treatment comparing EU/EEA countries [6]. There is however no data on the estimated proportion of migrants from endemic countries that are diagnosed. The data reported, as well as the strategies and interventions suggested, in this study can contribute to increasing the proportion of cases of $\mathrm{CHC}$ diagnosed and on treatment.

Previous studies of hepatitis B/C screening implemented among migrant populations describe different models. These include: outreach offering awareness raising and/or on-site screening by public health teams in social, civic or cultural locations familiar to the target community [29-31]; invitation-based screening where municipal, population or patient registries are used to send postal invitations to attend screening to people born in higher prevalence countries [32, 33]; opportunistic offering of screening to patients with country of birth-related risk factors who attend health care services for other health issues [34, 35]; and adding viral hepatitis screening to an existing screening programme, such as for tuberculosis, that targets people from high prevalence countries [36]. Each of these models differs in terms of logistical and resource requirements, uptake and case yield, but few studies have compared the characteristics and effectiveness of different models [37]. The characteristics of screening programmes that have demonstrated success in uptake and yield include: involvement of the community in planning and raising awareness; provision of screening in suitable and accessible locations for the target community; provision of language support, for example, translated materials and interpreters; planning and provision for people without health insurance coverage; cultural sensitivity about and efforts to reduce or eliminate stigma; and availability of follow-up and care in the community. Retention within a follow-up care and treatment pathway is crucial to ensure that the public health benefits of screening are realised [38]. A summary of migrant-specific screening programmes, an appraisal of factors contributing to success, and a range of other scientific and practical resources are available as part of the HEPscreen Toolkit, produced by the EU-funded HEPscreen project, which focused on screening for chronic viral hepatitis among migrants [39].

In four countries, (Cyprus, Lichtenstein, Luxembourg and the Netherlands) the upper range of the estimated relative contribution of migrants as a proportion of the total number of estimated cases was found to be over $100 \%$. This reflects unmeasured correlation between the input parameters (prevalence in countries of birth and the size of the migrant population) for the Delta method as well as the strong skew in the distribution of cases in the general population in these countries. It is also possible that the prevalence in the general population in these EU/EEA countries is under-estimated, due to unrepresentative sampling or low participation of risk populations who are harder to reach, such as PWID and ethnic minorities as well as migrants. Underrepresentation of migrants and ethnic minorities is a widely recognised phenomenon in clinical trial and health survey research, $[40,41]$ although literature specifically focused on sero-prevalence sampling and uptake is very limited [23]. In addition, it is possible that estimates based on prevalence in countries of birth results in over-estimation of the prevalence among migrants. For example, it is probable that no longer living in a high prevalence country would reduce the risk of transmission of $\mathrm{HCV}$, especially since much of the transmission in higher prevalence countries is nosocomial [42] and most EU/EEA countries have successfully controlled nosocomial transmission through health care infection control procedures. Over-estimation may also be due to the characteristics of migrants to the EU/EEA, who may be younger and healthier, and so less likely to have experienced hospitalisation or serious medical intervention and more likely to have benefited from improved primary prevention in the last two decades. Migrants to the EU may also be from higher socioeconomic groups in their countries of birth and able to afford better, safer health care [43]. We sought to test out this theory of over-estimation and found that, for just three of the ten countries of birth for which we retrieved estimates for, $[15,29,30,44-47]$ the prevalence 
in migrants was lower than the reported in-country prevalence.

Despite the systematic nature of data retrieval, there are some data limitations. Detailed demographic data was available from Eurostat for only 21 EU/EEA countries. There is also heterogeneity in the parameters and methods used by the different demographic databases and in the way that demographic data on migration is collected and reported by EU/EEA countries. From other literature, we know that countries such as Germany, France and the Netherlands require municipal registration upon arrival in a new area and collect country of birth data as part of registration. Other countries, like the UK, rely on population census data to systematically collect population size and origin [48]. However, there is very limited information in the literature on the methods used by each database or on the heterogeneity of demographic data collection methods across the EU/EEA. Despite these differences, the demographic data used in this study are derived from databases that in turn derive data from national statistical institutes. We believe it to be the best and most reputable available. These analyses do not include undocumented migrants, partly because the size and origin of this population is very dynamic, but mostly because of the imprecision and unreliability of the data [49]. The use of systematic reviews and meta-analyses for the country of birth prevalence input has reduced the reliance on less reliable single study estimates, and whilst we critically appraised the quality of the systematic reviews and meta-analyses, which all applied quality criteria to select studies, we did not directly assess the quality of the estimates included in these reviews. A further note of caution relates to the studies retrieved on prevalence in migrants, as just ten countries of birth were represented in the estimates and few studies had the specific aim of estimating the prevalence in migrants. The use of convenience sampling in many of these studies increases the chance of selection bias and, specifically, that people already diagnosed may not present for screening.

\section{Conclusions}

Advances in antiviral treatment open up the possibility of eliminating hepatitis $\mathrm{C}$ infection in Europe, but achieving this will require countries to scale up and better target screening, linkage to care and treatment. This study provides strategic, timely and detailed epidemiological intelligence for EU/EEA countries on the hepatitis $\mathrm{C}$ burden among migrant populations, a key population group affected by this infection in Europe. It also provides prevalence estimates for 224 countries and territories, which should serve as a useful resource for other countries and regions wishing to understand the relative contribution of migrants to the burden of hepatitis $\mathrm{C}$. This intelligence, together with the learning from previous migrant-specific screening projects in the EU/EEA [39], can help to inform the design of screening programmes to reach migrant populations most affected by chronic hepatitis $C$ infection. A targeted approach in higher risk populations makes more effective use of health care resources and contributes to reducing health inequalities. The World Health Organisation's Global Strategy for Viral Hepatitis [50] and the European Action Plan [51] both share the ambitious goal of elimination of viral hepatitis by 2030 . If this goal is to be realised, it will be essential to dramatically increase the proportion of people who are diagnosed, aware of their infection and on treatment. Future research can contribute by focussing on improving the evidence base on effective strategies to reach and retain migrant and other risk populations in screening and treatment and on costeffectiveness across the treatment cascade.

\section{Additional file}

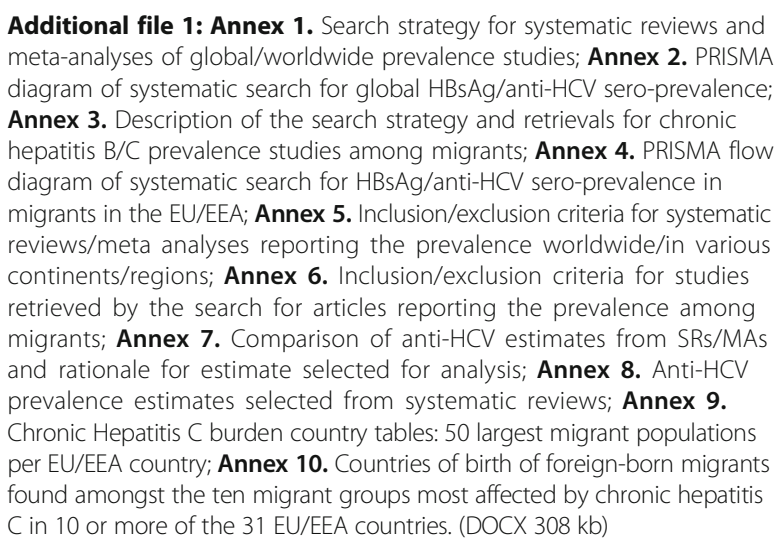

\section{Abbreviations \\ CHC: Chronic hepatitis c; Cls: Confidence Intervals; DAAs: Direct acting antivirals; ECDC: European centre for disease prevention and control; EU/EEA: European Union/European Economic Area; GBD: Global burden of disease; HCC: Hepatocellular carcinoma; HCV: Hepatitis C virus; OECD: Organisation for economic co-operation and development; PRISMA: Preferred reporting items for systematic reviews and meta analyses; PWID: People who inject drugs; UK: United Kingdom; WHO: World Health Organisation}

\section{Acknowledgements}

Wichor Bramer (Medical Librarian, Erasmus MC) for assistance with the systematic search queries. Jelle Koopson (RIVM), Daan Nieboer (Statistician, Department of Public Health, Erasmus MC) and Dr. Luc Coffeng (Assistant Professor, Department of Public Health, Erasmus MC) for statistical advice regarding the comparison of in-country with migrant derived prevalence estimates. Dr. Jan van de Kassteele (Statistician, RIVM) for assistance with the Delta method to derive the relative contribution range.

\section{Funding}

This study was funded by the European Centre for Disease Control and Prevention (ECDC) under contract number ECD.4999. The ECDC contributed to the design of the study, the interpretation of the results and the drafting/ editing of the manuscript. 


\section{Availability of data and materials}

An extensive supplementary annex of data and materials including the two detailed search strategies, inclusion and exclusion criteria, PRISMA flowcharts, selected country level estimates used in the calculations and an epidemiological profile of the contribution of migrants to the burden of $\mathrm{CHB}$ and $\mathrm{CHC}$ for each EU/EEA member state is available online. Other datasets used and/or analysed during the current study are available from the corresponding author on reasonable request.

\section{Authors' contributions}

AMF: study concept and design, literature search, acquisition of data, analysis and interpretation of data, drafting of the manuscript and critical revision of the manuscript for important intellectual content. AAA: study concept and design, literature search, acquisition of data, analysis and interpretation of data, drafting of the manuscript and critical revision of the manuscript for important intellectual content. ED: study concept and design, interpretation of data, critical revision of the manuscript for important intellectual content, supervised the study, and obtained funding. TN: study concept and design, interpretation of data, critical revision of the manuscript for important intellectual content, supervised the study, and obtained funding. IKV: study concept and design, literature search, analysis and interpretation of data, critical revision of the manuscript for important intellectual content, and supervised the study. All authors read and approved the final manuscript.

\section{Ethics approval and consent to participate}

Not applicable. This epidemiological study does not involve primary or experimental research in human subjects. It instead draws on freely available, public secondary data. It therefore falls outside the scope of medical ethical guidelines to which the corresponding author is bound.

\section{Consent for publication}

Not applicable.

\section{Competing interests}

All authors declare that they have no competing interests.

\section{Publisher's Note}

Springer Nature remains neutral with regard to jurisdictional claims in published maps and institutional affiliations.

\section{Author details}

'Department of Public Health, Erasmus MC, University Medical Center Rotterdam, Rotterdam, the Netherlands. ${ }^{2}$ Division of Infectious Disease Control, Municipal Public Health Service Rotterdam-Rijnmond, PO Box 70032 3000, LP, Rotterdam, The Netherlands. ${ }^{3}$ Department of Health Sciences, Hamburg University of Applied Sciences, Faculty Life Sciences / Public Health Research, Ulmenliet 20, 21033 Hamburg, Germany. ${ }^{4}$ Department of Internal Medicine, University Medical Center Hamburg-Eppendorf, Martinistr 52, 20246 Hamburg, Germany. ${ }^{5}$ European Centre for Disease Prevention and Control, Granits väg 8, 17165 Solna, Sweden. ${ }^{6}$ Center for Infectious Disease Control, National Institute for Public Health and the Environment, Bilthoven, the Netherlands.

\section{Received: 31 March 2017 Accepted: 11 December 2017}

\section{Published online: 16 January 2018}

\section{References}

1. Gower $\mathrm{E}$, et al. Global epidemiology and genotype distribution of the hepatitis C virus infection. J Hepatol. 2014;61(1):S45-57.

2. Mohd Hanafiah $\mathrm{K}$, et al. Global epidemiology of hepatitis $\mathrm{C}$ virus infection: new estimates of age-specific antibody to HCV seroprevalence. Hepatology. 2013;57(4):1333-42.

3. Lozano R, et al. Global and regional mortality from 235 causes of death for 20 age groups in 1990 and 2010: a systematic analysis for the global burden of disease study 2010. Lancet. 2012;380(9859):2095-128.

4. European Association for the Study of the Liver (EASL). EASL clinical practice guidelines: management of hepatitis C virus infection. J Hepatol. 2014;60(2): 392-420.

5. Wolffram I, et al. Prevalence of elevated ALT values, HBsAg, and anti-HCV in the primary care setting and evaluation of guideline defined hepatitis risk scenarios. J Hepatol. 2015;62(6):1256-64.
6. Collaborators TE. Hepatitis $\mathrm{C}$ virus prevalence and level of intervention required to achieve the WHO targets for elimination in the European Union by 2030: a modelling study. Lancet Gastroenterol Hepatol. 2017;2(5):325-36.

7. European Liver Patients Association (ELPA), Report on hepatitis patient selfhelp in Europe. Brussels: European Liver Patients Assocation; 2010.

8. Kohli A, et al. Treatment of hepatitis C: a systematic review. JAMA. 2014; 312(6):631-40

9. Wedemeyer $\mathrm{H}$, et al. Strategies to manage hepatitis $\mathrm{C}$ virus (HCV) disease burden. J Viral Hepat. 2014;21(Suppl 1):60-89.

10. Razavi $\mathrm{H}$, et al. The present and future disease burden of hepatitis $\mathrm{C}$ virus (HCV) infection with today's treatment paradigm. J Viral Hepat. 2014; 21(Suppl 1):34-59.

11. Negro F. Epidemiology of hepatitis C in Europe. Dig Liver Dis. 2014;46(Suppl 5): S158-64.

12. Deuffic-Burban $\mathrm{S}$, et al. Predicted effects of treatment for HCV infection vary among European countries. Gastroenterology. 2012;143(4):974-85. e14

13. Hope VD, et al. Prevalence and estimation of hepatitis $B$ and $C$ infections in the WHO European region: a review of data focusing on the countries outside the European Union and the European free trade association. Epidemiol Infect. 2014;142(2):270-86.

14. Buggisch $P$, et al. High prevalence of chronic hepatitis C in 8009 patients with migration background living in Germany. J Hepatol. 2013;58:S325.

15. Urbanus AT, et al. Hepatitis $C$ in the general population of various ethnic origins living in the Netherlands: should non-western migrants be screened? J Hepatol. 2011;55(6):1207-14.

16. Jafferbhoy $\mathrm{H}$, et al. The effectiveness of outreach testing for hepatitis $\mathrm{C}$ in an immigrant Pakistani population. Epidemiol Infect. 2012;140(6):1048-53.

17. Eurostat. Immigration by five-year age group, sex and country of birth [migr_imm3ctb]. 2013 [cited 2015; Available from: http://appsso.eurostat.ec. europa.eu/nui/show.do?dataset=migr_imm3ctb\&lang=en.

18. European Statistical System. EU 2011 - housing and Polulation census. 2011; Available from: https://ec.europa.eu/CensusHub2/.

19. Organisation for Economic Cooperation and Development (OECD). International migration database. 2013; Available from: http://stats.oecd.org/ Index.aspx?DatasetCode=MIG.

20. Lithuanian National Statistics Service. International migration flows. 2013; Available from: http://osp.stat.gov.lt/en/temines-lenteles1.

21. Casella G, Berger RL. Statistical inference. Michigan: Thomson Learning; 2002.

22. Bruggmann $\mathrm{P}$, et al. Historical epidemiology of hepatitis $\mathrm{C}$ virus (HCV) in selected countries. J Viral Hepat. 2014;21(Suppl 1):5-33.

23. Cornberg $\mathrm{M}$, et al. A systematic review of hepatitis $\mathrm{C}$ virus epidemiology in Europe, Canada and Israel. Liver Int. 2011;31(Suppl. 2):30-60.

24. Godzik P, et al. Prevalence of anti-HCV antibodies among adults in Polandresults of cross-sectional study in general population. Przegl Epidemiol, 2012;66(4):575-80

25. Lehman EM, Wilson ML. Epidemiology of hepatitis viruses among hepatocellular carcinoma cases and healthy people in Egypt: a systematic review and meta-analysis. Int J Cancer. 2009;124(3):690-7.

26. Waheed $\mathrm{Y}$, et al. Hepatitis $\mathrm{C}$ virus in Pakistan: a systematic review of prevalence, genotypes and risk factors. World J Gastroenterol. 2009;15(45):5647-53.

27. Gane $E_{1}$ et al. Strategies to manage hepatitis $\mathrm{C}$ virus (HCV) infection disease burden - volume 2. J Viral Hepat. 2015;22(Suppl 1):46-73.

28. Brady JE, et al. Uptake of hepatitis C screening, characteristics of patients tested, and intervention costs in the BEST-C study. Hepatology. 2016;65(1):44-53.

29. Uddin $\mathrm{G}$, et al. Prevalence of chronic viral hepatitis in people of south Asian ethnicity living in England: the prevalence cannot necessarily be predicted from the prevalence in the country of origin. J Viral Hepatitis. 2010;17(5):327-35.

30. O'Leary MC, et al. The prevalence of hepatitis $C$ virus among people of south Asian origin in Glasgow - results from a community based survey and laboratory surveillance. Travel Med Infect Dis. 2013;11(5):301-9.

31. Veldhuijzen IK, et al. Identification and treatment of chronic hepatitis B in Chinese migrants: results of a project offering on-site testing in Rotterdam, the Netherlands. J Hepatol. 2012;57(6):1171-6.

32. Richter $C$, et al. Screening for chronic hepatitis $B$ and $C$ in migrants from Afghanistan, Iran, Iraq, the former soviet republics, and Vietnam in the Arnhem region, The Netherlands. Epidemiol Infect. 2014;142(10):2140-6.

33. van der Veen $Y$ J, et al. Cultural tailoring to promote hepatitis B screening in Turkish Dutch: a randomized control study. Health Promot Int. 2014;29(4): 692-704.

34. Bottero J, et al. Current state of and needs for hepatitis B screening: results of a large screening study in a low-prevalent, metropolitan region. PLoS One. 2014:9(3). 
35. Heidrich $B$, et al. High prevalence of hepatitis markers in immigrant populations: a prospective screening approach in a real-world setting. Eur J Gastroenterol Hepatol. 2014;26(10):1090-7.

36. Barnett ED. Infectious disease screening for refugees resettled in the United States. Clin Infect Dis. 2004;39(6):833-41.

37. Rein DB, et al. Models of community-based hepatitis B surface antigen screening programs in the U.S. and their estimated outcomes and costs. Public Health Rep. 2011;126(4):560-7.

38. Miners AH, et al. Assessing the cost-effectiveness of finding cases of hepatitis $C$ infection in UK migrant populations and the value of further research. J Viral Hepat. 2014;21(9):616-23.

39. The HEPscreen Project. 2015; Available from: www.hepscreen.eu.

40. Murthy VH, Krumholz HM, Gross CP. Participation in cancer clinical trials: race-, sex-, and age-based disparities. JAMA. 2004;291(22):2720-6.

41. Downing NS, et al. Participation of the elderly, women, and minorities in pivotal trials supporting 2011-2013 U.S. Food and Drug Administration approvals. Trials. 2016;17:199.

42. Sievert W, et al. A systematic review of hepatitis $C$ virus epidemiology in Asia, Australia and Egypt. Liver Int. 2011;31(Suppl. 2):61-80.

43. Rechel B, et al. Migration and health in an increasingly diverse Europe. Lancet. 2013;381(9873):1235-45.

44. McPherson S, et al. Targeted case finding for hepatitis B using dry blood spot testing in the British-Chinese and south Asian populations of the north-east of England. J Viral Hepatitis. 2013;20(9):638-44.

45. Veldhuijzen IK, et al. Viral hepatitis in a multi-ethnic neighborhood in the Netherlands: results of a community-based study in a low prevalence country. Int J Infect Dis. 2009;13(1):e9-e13.

46. Richter C, et al. Hepatitis B prevalence in the Turkish population of Arnhem: implications for national screening policy? Epidemiol Infect. 2012;140(4):724-30.

47. Zuure FR, et al. Screening for hepatitis $B$ and $C$ in first-generation Egyptian migrants living in the Netherlands. Liver Int. 2013;33(5):727-38.

48. Rechel B, Mladovsky P, Deville W. Monitoring migrant health in Europe: a narrative review of data collection practices. Health Policy. 2012;105(1):10-6.

49. Clandestino - Database on irregular migration. http://irregular-migration.net// index.php?id=161. [cited 2015.

50. World Health Organisation (WHO). Global Health sector strategy on viral hepatitis 2016-2021: towards ending viral hepatitis. Geneva: World Health Organisation; 2016

51. World Health Organisation (WHO). Action plan for the health sector response to viral hepatitis in the WHO European region. Geneva: World Health Organisation; 2016.

52. Uddin G, et al. Prevalence of chronic viral hepatitis in people of south Asian ethnicity living in England: the prevalence cannot necessarily be predicted from the prevalence in the country of origin. J Viral Hepat. 2010;17(5):327-35.

53. McPherson S, et al. Targeted case finding for hepatitis B using dry blood spot testing in the British-Chinese and south Asian populations of the north-east of England. J Viral Hepat. 2013;20(9):638-44.

54. Zuure FR, et al. Reasons for compliance or noncompliance with advice to test for hepatitis $C$ via an internet-mediated blood screening service: a qualitative study. BMC Public Health. 2011;11:293.

\section{Submit your next manuscript to BioMed Central and we will help you at every step:}

- We accept pre-submission inquiries

- Our selector tool helps you to find the most relevant journal

- We provide round the clock customer support

- Convenient online submission

- Thorough peer review

- Inclusion in PubMed and all major indexing services

- Maximum visibility for your research

Submit your manuscript at www.biomedcentral.com/submit

) Biomed Central 